\title{
Targeted next-generation sequencing for research and diagnostics in congenital heart disease, and cleft lip and/or palate
}

\author{
HAISONG BU ${ }^{1}$, LIN LIU ${ }^{2}$, SHIJUN HU ${ }^{1}$, ZHIPING TAN $^{1}$ and TIANLI ZHAO ${ }^{1}$ \\ Departments of ${ }^{1}$ Cardiovascular Surgery, and ${ }^{2}$ Stomatology, The Second Xiangya Hospital, \\ Central South University, Changsha, Hunan 410011, P.R. China
}

Received September 25, 2018; Accepted March 8, 2019

DOI: $10.3892 / \mathrm{mmr} .2019 .10043$

\begin{abstract}
Congenital heart disease (CHD), and cleft lip and palate (CLP) are currently the most common types of structural malformation in infants. Various methods have been used to identify the disease-associated genes. However, targeted next-generation sequencing (NGS) is not yet considered an option for routine use. Thus, the present study aimed to assess the safety and feasibility of using targeted NGS in patients with CHD concomitant with CLP. Between November 2015 and May 2017, a total of 17 patients with CHD concomitant with CLP, who were excluded from a diagnosis of trisomy syndrome, were selected at The Second Xiangya Hospital of Central South University (Changsha, China). Genomic DNA was extracted from peripheral blood samples of the patients. The copy number variants (CNVs) were determined by conducting a single nucleotide polymorphism (SNP) array with Illumina HumanOmni1-Quad Beadchip, while information on other gene mutations was obtained from targeted sequencing. The functions of gene mutations were then predicted using the PolyPhen-2, SIFT and Mutation Taster tools. Finally, Sanger sequencing was used to verify the mutations. The results identified no pathogenic mutations in CNVs analyzed by high-throughput SNP sequencing. Targeted NGS results demonstrated that 10 patients $(58.8 \%)$ carried gene mutations, including $4(23.5 \%)$ genetically diagnosed cases and $6(35.3 \%)$ cases with unknown etiology. The 4 known diseases were Opitz G/BBB syndrome caused by MIDI
\end{abstract}

Correspondence to: Dr Tianli Zhao, Department of Cardiovascular Surgery, The Second Xiangya Hospital, Central South University, 139 Renmin Road, Changsha, Hunan 410011, P.R. China

E-mail: zhaotianli@csu.edu.cn

Abbreviations: CHD, congenital heart disease; CLP, cleft lip and palate; SNP, single nucleotide polymorphisms; CNVs, copy number variations; CL, cleft lip; $\mathrm{CP}$, cleft palate; NGS, next-generation sequencing; PCR, polymerase chain reaction; LDS, Loeys-Dietz syndrome; RSS, Ritscher-Schinzel syndrome

Key words: targeted next-generation sequencing, copy number variants, single nucleotide polymorphism array, congenital heart disease, cleft lip, cleft palate gene mutation, Loeys-Dietz syndrome caused by TGFBRI gene mutation, Ritscher-Schinzel/3C syndrome caused by KIAA0196 gene mutation and CHARGE syndrome caused by CHD7 gene mutation. The remaining 6 cases were not genetically diagnosed, although they carried candidate genes. In conclusion, the present study demonstrated that targeted NGS was an effective and accurate candidate gene detection method in patients with CHD concomitant with CLP.

\section{Introduction}

Congenital heart disease (CHD), and cleft lip and palate (CLP) represent birth defects with the highest rates of incidence worldwide. Furthermore, the incidence rate of CHD in patients with CLP is $6.5-12.7 \%$, which is notably higher in comparison with that of the general population $(1,2)$. In addition to distorting the facial appearance, CLP can negatively affect normal infant activities, such as suckling and speaking (3). Clinically, CHD and CLP are commonly referred to as the main phenotypes, although specific syndromes are also described in certain patients, such as velocardiofacial syndrome, solitary median maxillary central incisor syndrome and Wolf-Hirschhorn syndrome, among others (4-6). Children with CLP typically require multiple surgical interventions and numerous sessions of speech therapy from infancy to early adulthood to achieve near-normal appearance and function (7). Genetic studies have suggested that deletion of the chromosome fragments and single gene mutation are both observed in these syndromes (4-6,8). However, the hereditary background of patients with such syndromes currently remains clear.

With the development of genetic sequencing technologies, numerous novel methods have been suggested as important techniques to identify disease-associated genes, including single nucleotide polymorphism (SNP) array, copy number variation $(\mathrm{CNV})$ analysis, and targeted and whole exome sequencing (9-11). Traditionally, genetic testing in DNA-based diagnostic laboratories involves sequential Sanger sequencing of known disease genes. However, the diagnostic yield of next-generation sequencing (NGS) exceeds that of Sanger sequencing in genetic diseases, since multiple genes can be analyzed in a single experiment. Thus, the introduction of NGS has provided revolutionary opportunities for comprehensive genetic testing in research and diagnostics. 
In the present study, the effectiveness and accuracy of using targeted NGS to determine candidate genes in patients with CHD concomitant with CLP were assessed.

\section{Patients and methods}

Patients. A total of 17 patients with CHD concomitant with CLP treated at The Second Xiangya Hospital of Central South University (Changsha, China) between November 2015 and May 2017 were enrolled into the present study (Fig. 1). The study group comprised of 14 male and 3 female patients aged 4-108 months (mean age, 42.8 \pm 32.9 months) with a mean body weight of $17.6 \pm 6.9 \mathrm{~kg}$ (Table I). The patient selection criteria in terms of CHD were as follows: i) Exhibiting typical clinical manifestations and symptoms of CHD on physical examination, including cyanosis and/or cardiac murmur; and ii) diagnosis of CHD by transthoracic echocardiography (12). In terms of CLP the inclusion criteria included the following: i) Typical clinical manifestations and symptoms on physical examination, including cleft lip (CL) and/or cleft palate (CP) $(13,14)$; ii) stomatological diagnosis; and iii) amalgamation or non-merger of other malformations, or growth/mental retardation. The patient exclusion criteria were as follows: i) Patients without CHD and CLP; ii) cases diagnosed with trisomy 18 or 21 syndrome; and iii) refusal of participation by the patient's parents or guardians.

The study protocol was approved by the Review Board of The Second Xiangya Hospital of Central South University, and the relatives of study subjects provided informed consent for participation. All experiments were performed in accordance with relevant guidelines and regulations.

Blood sample collection and DNA extraction. Peripheral blood samples $(600 \mu 1)$ obtained from each patient were collected into $1.5 \mathrm{ml}$ Eppendorf tubes (Eppendorf, Hamburg, Germany) containing protein kinase $(20 \mu \mathrm{l})$ and cell lysate $(200 \mu \mathrm{l})$. Tubes were agitated for $1 \mathrm{~min}$, centrifuged for $10 \mathrm{sec}$ at $4^{\circ} \mathrm{C}$ at $9,295 \mathrm{x} \mathrm{g}$, and subjected to genomic (g)DNA extraction using a DNeasy Blood and Tissue kit (Qiagen, Inc., Valencia, CA, USA) according to the manufacturer's protocols using a QIAcube automated DNA extraction device (Qiagen, Inc.). The gDNA solution generated was stored at $-80^{\circ} \mathrm{C}$. Subsequently, a NanoDrop 2000 spectrophotometer (Thermo Fisher Scientific, Inc., Waltham, MA, USA) was used to determine the quantity and quality of the DNA samples, and $3 \mu \mathrm{g}$ DNA from each sample was then used in subsequent assays (15-17).

SNP array analysis. Genomic DNA samples of the patients were used to conduct SNP array analysis at a final concentration of $50 \mathrm{ng} / \mathrm{ml}$. The signal intensities of SNP probes were determined by employing an Illumina BeadScan genotyping system (Beadstation Scanner 500; Illumina, Inc., San Diego, CA, USA) with a HumanOmni1-Quad Beadchip (Illumina, Inc.), according to the manufacturer's protocol.

Targeted NGS. A targeted NGS gene panel for 455 genes that have been associated with CHD or CLP in previous studies $(8,16,18,19)$ was employed (Table II). Targeted NGS, including library construction, capture and sequencing, was performed by Agilent Technologies, Inc. (Santa Clara, CA, USA). Enrichment of target regions and library preparation were performed using a SureSelectXT2 Custom kit (1-499 kb; Agilent Technologies, Inc.) according to the manufacturer's protocol. Library DNA concentrations were determined using an Agilent QPCR NGS Library Quantification kit (G4880A; Agilent Technologies, Inc.), with each sample at a final concentration of $10 \mathrm{nmol} / \mathrm{l}$. Subsequently, samples were ordered with a HiSeq2000 sequencing system using TruSeq chemistry and protocols (version 3; Illumina, Inc.) (20).

Data analysis and filtering. The Ensembl database (release 95; https://www.ensembl.org/) was used for variant annotation. Filtering was performed with ANNOVAR Documentation (http://annovar.openbioinformatics.org/), using the following SNP databases for filtering: dbSNP (build 138; https://www.ncbi. nlm.nih.gov/snp),Exome VariantServer(release ESP6500SI-V2; http://evs.gs.washington.edu/EVS/), 1000 Genomes Project (released May 2012; http://www.internationalgenome. org/home) and HapMap CHB (release 28; http://hapmap.ncbi. nlm.nih.gov/). In order to predict the possible impact of variants, the following tools were used: SIFT (version 6.2.1, https://sift.bii.a-star.edu.sg/), Polyphen-2 (version 2.2.2; http://genetics.bwh.harvard.edu/pph2/), Mutation-Taster (version 2; http://www.mutationtaster.org/) and Human Splicing Finder (version 3.1, http://www.umd.be/HSF3/). The filtering strategies used are displayed in Fig. 2.

Variant validation. Variants warranting further investigation included novel variants, which were predicted to be 'likely pathogenic' or 'pathogenic' according to PolyPhen-2, Mutation-Taster and SIFT predictions, or were indicated to be 'likely pathogenic' and possessed minor allele frequencies of $<0.1 \%$, as predicted by ExAC browser (version 0.3.1; http://exac.broadinstitute.org/). Variants and samples from the parents of certain patients were assessed by Sanger sequencing. To confirm the disease-associated genes, the relevant literature was surveyed on PubMed (https://www.ncbi. nlm.nih.gov/pubmed); example literature searches included: MIDl, Opitz G/BBB syndrome, 2007.1.1-2018.10.31, English; TGFBR1,Loeys-Dietz syndrome, 2007.1.1-2018.10.31,English; KIAA0196, Ritscher-Schinzel syndrome, 2007.1.1-2018.10.31, English; CHD7, CHARGE syndrome, 2007.1.1-2018.10.31, English.

Polymerase chain reaction ( $P C R)$. Entire exon and exon-intron junctions of genes were amplified by PCR. Genomic DNA $(0.5 \mu \mathrm{l})$ obtained from peripheral blood samples of patients was added to $11 \mu 1$ double-distilled water, $0.5 \mu 1$ forward primer, $0.5 \mu \mathrm{l}$ reverse primer and 2x PCR Master Mix (12.5 $\mu \mathrm{l}$; Nanjing Saihongrui Biotechnology Co., Ltd., Nanjing, China) containing $2 \mathrm{X}$ Taq DNA Polymerase. qPCR was conducted as follows: Initial denaturation at $94^{\circ} \mathrm{C}$ for $5 \mathrm{~min} ; 35$ cycles of denaturation at $94^{\circ} \mathrm{C}$ for $30 \mathrm{sec}$, annealing at $50^{\circ} \mathrm{C}$ for $30 \mathrm{sec}$ and extension at $72^{\circ} \mathrm{C}$ degrees for $30 \mathrm{sec}$; and final extension at $72^{\circ} \mathrm{C}$ degrees for $10 \mathrm{~min}$. Sequences of the PCR products were determined using an ABI 3100 Genetic Analyzer (Applied Biosystems; Thermo Fisher Scientific, Inc.) according to the manufacturer's protocol. The primer sequences are listed in Table III. 


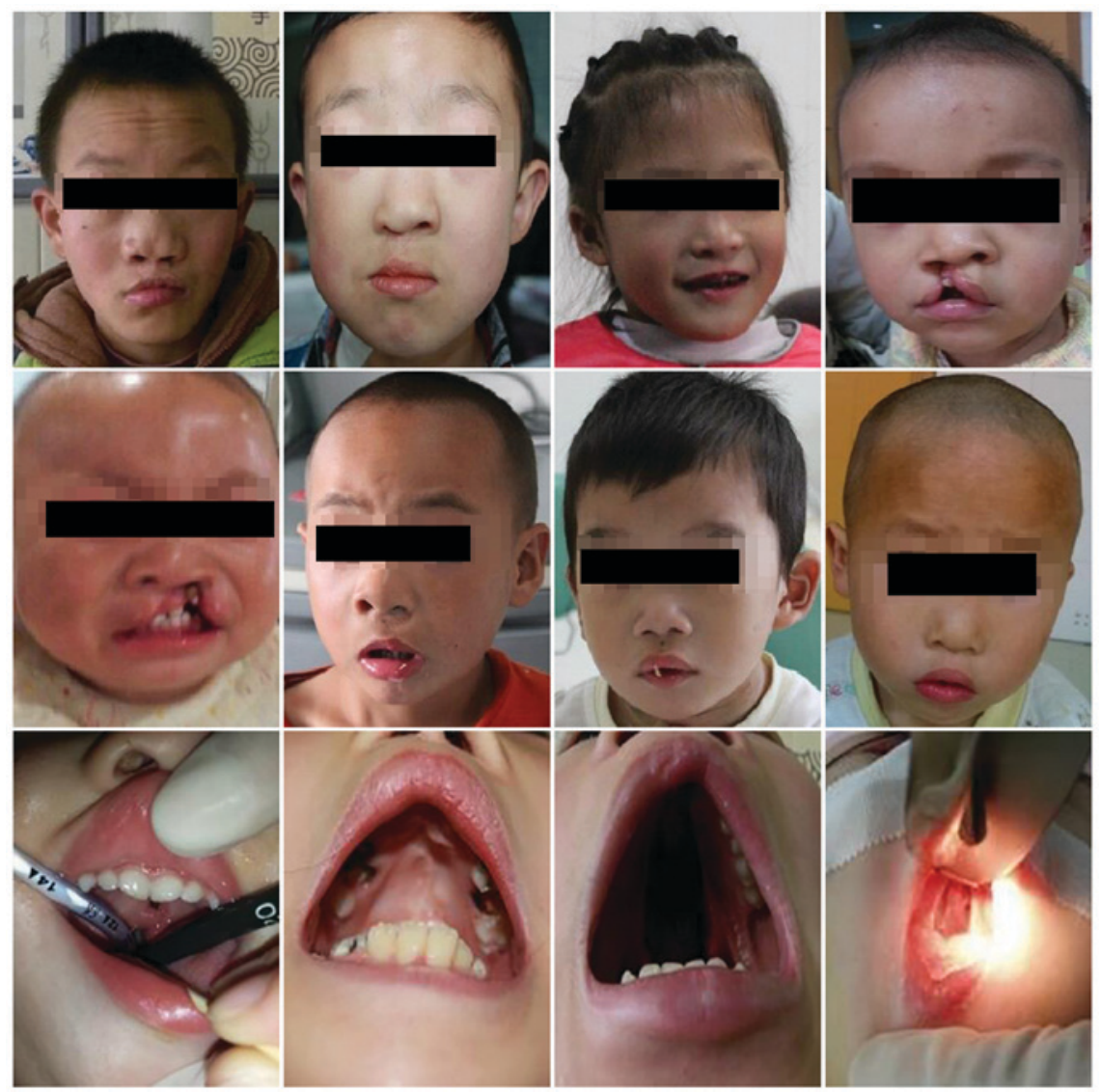

Figure 1. Characteristic examples of left lip and/or palate phenotype in patients.

\section{Results}

Screening outcomes. No pathogenic mutations were identified in CNVs analyzed by high-throughput SNP sequencing. The targeted NGS results demonstrated that 10 out of the 17 patients $(58.8 \%)$ carried gene mutations, including 4 cases $(23.5 \%)$ that were genetically diagnosed and 6 cases $(35.3 \%)$ with unknown etiology; the remaining 7 patients did not carry known mutations. The diseases involved in the 4 known cases and the associated genes were as follows: Opitz G/BBB syndrome caused by midline-1 (MIDI) gene mutation; Loeys-Dietz syndrome (LDS) caused by transforming growth factor- $\beta$ receptor type I (TGFBRI) gene mutation; Ritscher-Schinzel syndrome (RSS; also known as 3C syndrome) caused by KIAA0196 gene mutation; and CHARGE syndrome caused by chromodomain-helicase-DNA-binding protein 7 (CHD7) gene mutation.

Prediction of gene function. Characteristics of the named gene mutations were predicted through the PolyPhen-2, SIFT and Mutation Taster programs (Table IV). Among the genetically diagnosed cases, the MIDI (c.G1477C, p.A723V) and TGFBRI (c.T1400A, p.M467K) gene mutations were predicted to be 'pathogenic', 'likely pathogenic' and 'pathogenic' by SIFT, PolyPhen-2 and Mutation Taster, respectively. The $C H D 7$ gene mutation (c.C4894T, p.R1632C) was predicted to be 'pathogenic' by both SIFT and Mutation Taster, while the PolyPhen-2 program predicted this mutation to be 'benign'. The KIAA0196 gene mutation (c.A2533G, p.T845A) was predicted to be 'likely
Table I. Patient characteristics.

\begin{tabular}{lc}
\hline Characteristic & Value \\
\hline Total no. & 17 \\
Males/females & $14 / 3$ \\
Mean age (months) & $42.8 \pm 32.9$ \\
Mean weight (kg) & $17.6 \pm 6.9$ \\
Cardiac phenotype & \\
ASD & 1 \\
VSD & 7 \\
DORV & 1 \\
ASD + VSD & 3 \\
ASD + PLSVC & 1 \\
TOF + PLSVC & 1 \\
VSD + PFO & 1 \\
TOF + ASD & 1 \\
PDA + PFO & 1 \\
Maxillofacial phenotype & \\
CL & 5 \\
CP & 9 \\
CLP & 3 \\
\hline
\end{tabular}

VSD, ventricular septal defect; ASD, atrial septal defect; TOF, tetralogy of Fallot; PLSVC, persistent left superior vena cava; PDA, patent ductus arteriosus; PFO, patent foramen ovale; DORV, double outlet right ventricle; CLP, cleft lip and cleft palate; CP, cleft palate; CL, cleft lip. 


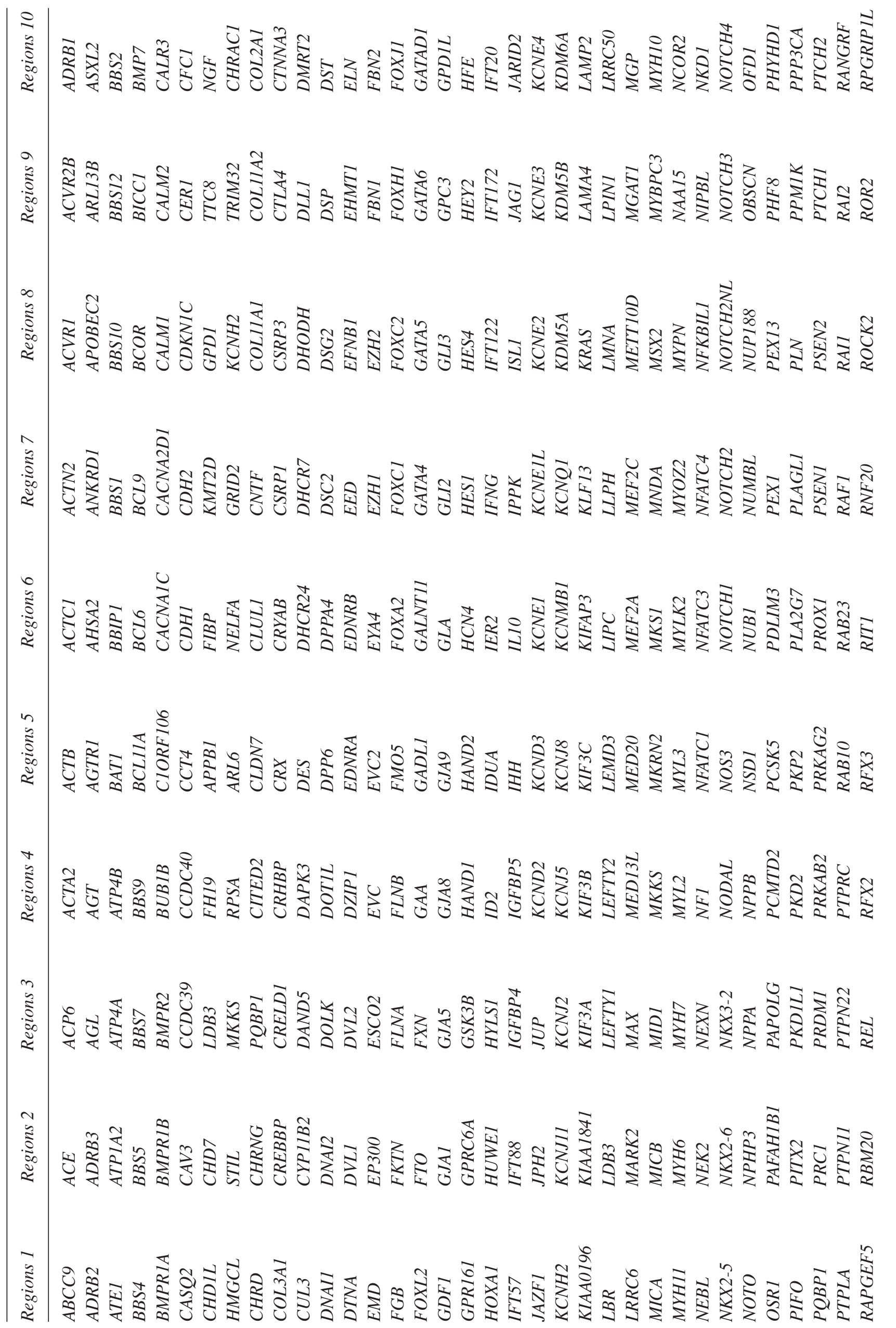




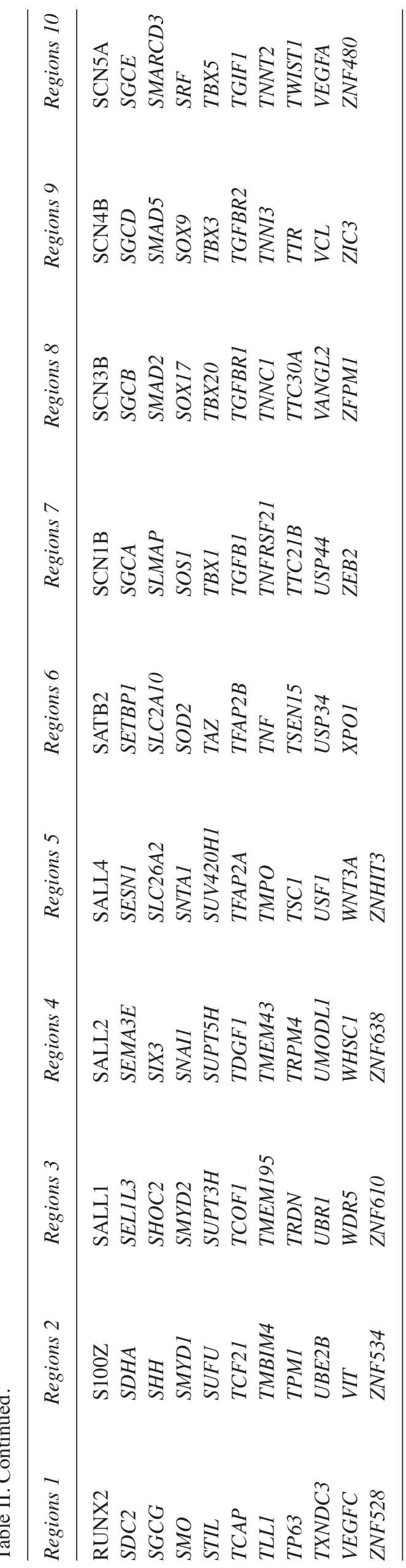

Table III. Primer sequences.

\begin{tabular}{|c|c|}
\hline Gene & Primers $\left(5^{\prime}-3^{\prime}\right)$ \\
\hline$M I D 1$ & $\begin{array}{l}\text { F: CACTTTGTGATAGGAGGCATGA } \\
\text { R: ACACATTTCCAGCTACTCCATAG }\end{array}$ \\
\hline TGFBR 1 & $\begin{array}{l}\text { F: CACCAGTACCCTATTGATGGAAA } \\
\text { R: AGTTCAGGCAAAGCTGTAGAA }\end{array}$ \\
\hline KIAA0196 & $\begin{array}{l}\text { F: CATATTTGGTGCCGCATGTC } \\
\text { R: AGAAGCCTGTCTAAGCCATTTA }\end{array}$ \\
\hline CHD7 & $\begin{array}{l}\text { F: AATGTTTCAGGGTGGAGA } \\
\text { R: CAGGACCTTGTTACAGTGAT }\end{array}$ \\
\hline NPHP3 & $\begin{array}{l}\text { F: CACAATGCAGTATAGCACACAAA } \\
\text { R: CTTATCTGTTCCAGCCACACT }\end{array}$ \\
\hline PCSK5 & $\begin{array}{l}\text { F: GTGCCTTGTTAATCCCTTTACAC } \\
\text { R: CAGGCTGCTCTTGCTCTT }\end{array}$ \\
\hline$F B N 2$ & $\begin{array}{l}\text { F: TAATGAGTGTGTCGCCCTTC } \\
\text { R: TGGCACTTAGTATGTTTCCAGAG }\end{array}$ \\
\hline DLL1 & $\begin{array}{l}\text { F: CTGTCTTTGGTTTGTCTGGTTTC } \\
\text { R: AAGTCGTTCACGCCATCC }\end{array}$ \\
\hline NOTCH3 & $\begin{array}{l}\text { F: TCCTAAACTCACCCTGTCCT } \\
\text { R: GCACAGTCGTAAGTGAGGTC }\end{array}$ \\
\hline COL3A1 & $\begin{array}{l}\text { F: AAGCAGCATCACTGTCATCTAA } \\
\text { R: AGAACTGCCCATTTGTGGT }\end{array}$ \\
\hline CHDIL & $\begin{array}{l}\text { F: GAACTCGCTCTGAGGTTCAA } \\
\text { R: AACTTCTAAGGTCACAGGTTAGG }\end{array}$ \\
\hline FMO5 & $\begin{array}{l}\text { F: GCTGAGTAAAGAGAACACTTGGA } \\
\text { R: TGGCTGTTTGGCTAATCTCTAC }\end{array}$ \\
\hline$L L P H$ & $\begin{array}{l}\text { F: GGATGAACCAAAGGCAAAGAAA } \\
\text { R: GAGGAGTTATGCTGGGTTTGA }\end{array}$ \\
\hline PPARGCIA & $\begin{array}{l}\text { F: GGATGAACCAAAGGCAAAGAAA } \\
\text { R: GAGGAGTTATGCTGGGTTTGA }\end{array}$ \\
\hline PTPN22 & $\begin{array}{l}\text { F: GGACATAGAGCTGAATTTGCTTC } \\
\text { R: CAAAGACAAGCTCTCTATAAGGTAGA }\end{array}$ \\
\hline ТТСЗОА & $\begin{array}{l}\text { F: GGAACTCTTTATTGTGCCAAAGG } \\
\text { R: CTGGACTCATCTGTGACTGTATTC }\end{array}$ \\
\hline OBSCN & $\begin{array}{l}\text { F: CCACGCTGGACTCCATTAG } \\
\text { R: GCACAGATGGGTGGATGAA }\end{array}$ \\
\hline DAND5 & $\begin{array}{l}\text { F: GTCATTGCTCCTCTCTCTACATC } \\
\text { R: ACGTCTTTCTTGGTCCATCTC }\end{array}$ \\
\hline STIM2 & $\begin{array}{l}\text { F: CTAGAGCTTGTGCATGGGAA } \\
\text { R: GACTTTGCTCTGCAGTTTGTAAG }\end{array}$ \\
\hline
\end{tabular}

F, forward; R, reverse; MID1, midline-1; TGFBR1, transforming growth factor- $\beta$ receptor type I; $C H D 7$, chromodomain-helicaseDNA-binding protein 7; NPHP-3, nephrocystin-3; PCSK5, proprotein convertase subtilisin/kexin type $5 ; F B N 2$, fibrillin 2; $D L L 1$, delta-like protein 1; NOTCH3, Notch 3; COL3A1, collagen type III $\alpha 1$ chain; $C H D 1 L$, chromodomain helicase DNA binding protein 1 like; FMO5, flavin containing monooxygenase 5; $L L P H$, LLP homolog, long-term synaptic facilitation factor; PPARGC1A, peroxisome proliferator activated receptor gamma coactivator 1 alpha; PTPN22, protein tyrosine phosphatase non-receptor type 22; TTC30A, tetratricopeptide repeat domain 30A; OBSCN, obscurin; DAND5, DAN domain BMP antagonist family member 5; STIM2, stromal interaction molecule 2. 


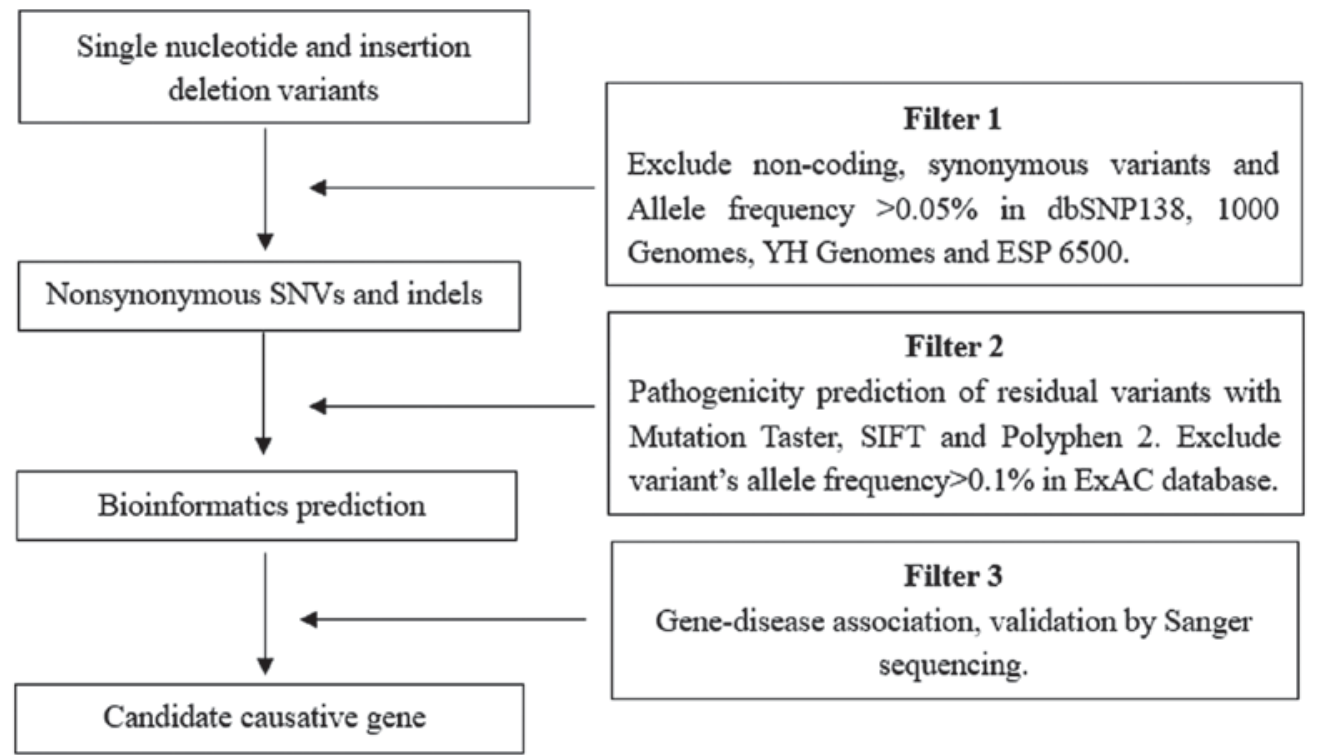

Figure 2. Flow chart representing the filtering strategies employed in the present study.

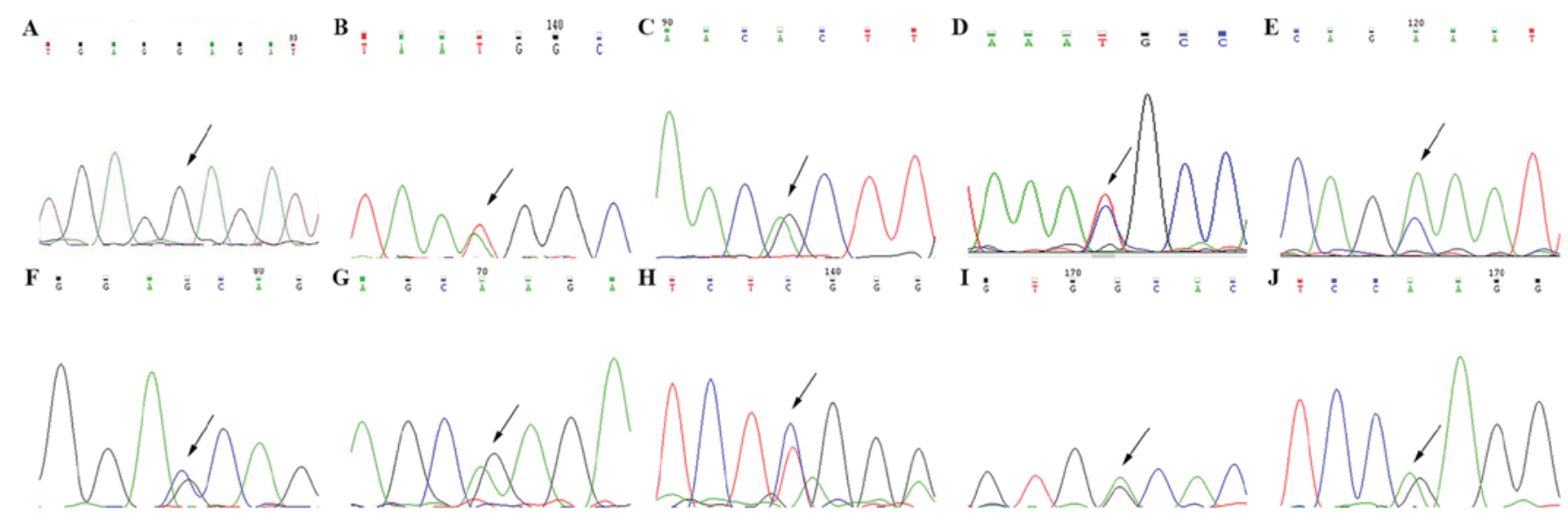

Figure 3. Results of Sanger sequencing. Results for patients 1 to 10 are presented in graphs A-J, respectively. The first four patients were diagnosed as follows: Patient 1, Opitz G/BBB syndrome; patient 2, Loeys-Dietz syndrome; patient 3, Ritscher-Schinzel syndrome; and patient 4, CHARGE syndrome.

pathogenic' by PolyPhen-2 and 'pathogenic' by Mutation Taster, while the SIFT program predicted this mutation to have 'uncertain significance'. Potential pathogenic genes were identified in the remaining 6 cases; however, literature searches did not reveal previously reported associations between the genes and diseases of interest. Therefore, the cases cannot be diagnosed based upon the identified mutations.

Sanger sequencing. Finally, Sanger sequencing verified each mutation (Fig. 3), which was followed by review of the literature in the context of each mutation to obtain the genetic diagnosis $(8,21-23)$. The parents of certain patients were also studied through the use of Sanger sequencing, but the identified gene mutations were not detected in any of the parents (data not shown).

\section{Discussion}

CHD and CLP are characterized by anomalous anatomical structures, caused by abnormal development of the heart and large blood vessels in CHD (24), or abnormal fusion of the lip and palate during embryonic development in CLP (25). These diseases can severely affect neonatal health, thus representing a burden to families and the society (16). With the rapid development of genetic sequencing technology, a number of methods are considered to be important in identifying disease-associated genes, including Sanger sequencing, SNP array, CNV analysis, and targeted and whole exome sequencing.

In the current study, no pathogenic mutations were identified in CNVs analyzed by high-throughput SNP sequencing. Certain gene mutations were successfully identified in 10 patients $(58.8 \%)$ via targeted NGS. According to the clinical phenotype of the patient and the mutation site of the candidate pathogenetic gene, 4 of these patients were diagnosed with a known genetic syndrome. To the best of our knowledge, it appears that the present study identified for the first time a mutation (c.G1477C, p.A723V) in the MIDl gene as a possible cause of ventricular septal defect and CL in an 


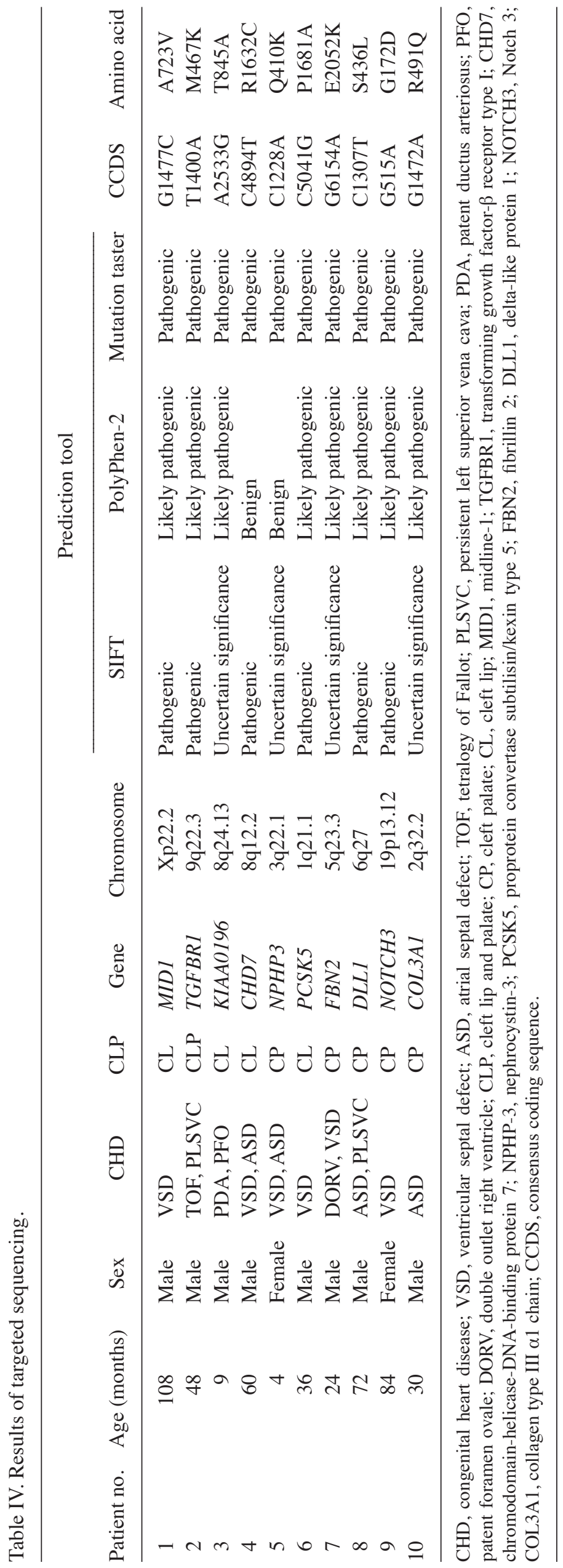


Opitz G/BBB syndrome patient. The MIDl gene is located on the short arm of the $\mathrm{X}$ chromosome, is approximately $300 \mathrm{~kb}$, and includes 9 coding exons and multiple non-coding exons. In early embryonic development, the MIDl gene is highly expressed in the heart, facial region and central nervous system $(26,27)$. In total, $>90$ different mutations of the $M I D 1$ gene have been reported in the literature, and point mutations in this gene have been suggested to cause Opitz G/BBB syndrome $(18,21,28-31)$. The MID1 protein encoded by the MIDl gene is a ubiquitin ligase that interacts with the $\alpha 4$ protein, which is linked to the protein phosphatase PP2A and forms the complex MID1- $\alpha 4$-PP2A (27,32). This complex is closely associated with the development of the ventral midline; therefore, this is also the main reason for the abnormal development of the ventral midline structure caused by MID1 gene mutation (33).

LDS is characterized by vascular abnormalities (cerebral, thoracic, and abdominal arterial aneurysms and/or dissections), skeletal manifestations, craniofacial features (such as CP) and cutaneous findings (34). Approximately a third of LDS cases are caused by TGFBR1 mutation, while two thirds are caused by $T G F B R 2$ mutation; the mutation site is mostly located in the serine-hydroxybutyrate enzyme activation coding region, located in the intracellular portion of the TGF- $\beta$ receptor (35). The TGF- $\beta$ type I receptor is necessary for the fusion of the upper lip and soft palate $(36,37)$, and the TGFBRl gene serves a major role in the development of the heart (22). In the present study, the TGFBR1 gene mutation was predicted to be 'pathogenic', 'likely pathogenic' and 'pathogenic' by the SIFT, PolyPhen-2 and Mutation Taster programs, respectively. It was also identified for the first time that mutation (c.T1400A, p.M467K) in the TGFBRl gene was a possible cause of tetralogy of Fallot and CL in the LDS patient.

RSS is a clinically heterogeneous disorder characterized by distinctive craniofacial features (including $\mathrm{CP}$ ) in addition to cerebellar and cardiac anomalies (8). To date, two articles $(8,38)$ have been reported on cases of RSS caused by KIAA0196 gene mutation. Mutation (c.A2533G, p.T845A) in KIAA0196 gene was investigated in the present study, which is a novel candidate gene involved in heart development. The KIAA0196 gene is situated at 8q24.13 of chromosome 8, and the encoded protein of this gene is known as strumpellin, which is comprised of 1,159 amino acids and is highly conserved (8). This protein is ubiquitously expressed in multiple systems and is highly expressed in skeletal muscle. KIAA0196 mutations have been reported to cause hereditary spastic paraplegia (39), while a complex overlapping phenotype, particularly with $\mathrm{CHD}$, has been rarely reported. In 2013, Elliott et al (8) detected KIAA0196 gene mutations in 8 patients with $\mathrm{RSS} / 3 \mathrm{C}$ syndrome. The expression of strumpellin protein was also reduced by $60 \%$, and the patients exhibited abnormal phenotype of heart development defects. In addition, previous studies have indicated that there are genes that cause cardiac abnormalities in the $8 \mathrm{q} 24$ interval, and suggested that the KIAA0196 gene is incorporated into the interval $(8,40)$. These studies also suggested that the KIAA0196 gene may serve a role in the pathogenesis of cardiac developmental disorders.

CHARGE syndrome is a congenital condition comprising of choroid disease, heart disease, atresia choanae, retarded growth and development, genital hypoplasia, and ear anomalies and/or deafness; facial palsy, micrognathia, CP and swallowing difficulties are also common (41). In the present study, the $C H D 7$ gene mutation (c.C4894T, p.R1632C) was predicted to be 'pathogenic' by both SIFT and Mutation Taster, while the PolyPhen-2 program predicted this mutation to be 'benign'. To date, 193 mutations of the CHD7 gene have been reported to lead to CHARGE syndrome $(23,42)$. The $C H D 7$ gene encodes the CHD7 protein, which serves a role in chromatin remodeling, cell cycle regulation, apoptosis regulation, transcriptional regulation and embryonic stem cell diversity (43). Studies have demonstrated that the $C H D 7$ gene is expressed in a number of fetal tissues, including the fetal eye, ear, brain cells, olfactory bulb and heart tube, among others $(19,43)$. The majority of mutations lead to the production of non-functional CHD7 protein, which may disrupt chromatin remodeling and gene expression. Regulation changes in $C H D 7$ gene expression during embryonic development may lead to symptoms and signs of CHARGE syndrome (19).

The remaining 6 cases were not genetically diagnosed, although candidate genes were identified, including nephrocystin-3 (NPHP-3), proprotein convertase subtilisin/kexin type 5 (PCSK5), fibrillin 2 (FBN2), delta-like protein 1 (DLL1), Notch 3 (NOTCH3) and collagen type III $\alpha 1$ chain (COL3Al). The NPHP3 gene mutation (c.C1228A, p.Q410K) may impact the development of cilia tissue, while it has been reported that primary ciliary dyskinesia is associated with the development of CHD (44). In addition, the PCSK5 gene mutation (c.C5041G, p.P1681A) was predicted to be 'pathogenic', 'likely pathogenic' and 'pathogenic' by the SIFT, PolyPhen-2 and Mutation Taster tools, respectively. In mice, the PCSK5 gene causes VACTERL syndrome, which comprises of deformity in vertebral, anorectal, cardiac, tracheoesophageal, renal, limb and other systems (45). The FBN2 gene mutation (c.G6154A, p.E2052K) may cause congenital contractural arachnodactyly. The cardiovascular phenotype of this syndrome is milder and less common in comparison with that of Marfan syndrome, and the ascending aorta is also slightly dilated, which may be combined with other intracardiac malformations (46). Furthermore, the SIFT, PolyPhen-2 and Mutation Taster programs respectively predicted the DLL1 gene mutation (c.C1307T, p.S436L) to be 'pathogenic', 'likely pathogenic' and 'pathogenic'. The protein encoded by the DLL1 gene is a ligand in the Notch signaling pathway, which mainly regulates the apoptosis of hematopoietic cells and signals between cells. The Notch signaling pathway serves an important role in embryonic differentiation and in homeostasis in adults, as well as in the development of various systems (47). Additionally, the protein encoded by the NOTCH3 gene, which was found to be affected by mutation (c. G515A, p. G172D) in the present study, is among the key proteins in the Notch signaling pathway. The disease caused by the mutation is an autosomal dominant arteriopathy associated with subcortical infarcts and leukoencephalopathy (48). Although CHD or CLP caused by mutations in the NOTCH3 gene has not been reported to date, the role of the Notch signaling pathway in the growth and development of various systems is widely recognized (47). The COL3A1 gene mutation (c.G1472A, p.R491Q) was predicted to be 'likely pathogenic' and 'pathogenic' by PolyPhen-2 and Mutation Taster, respectively, whereas the SIFT program 
predicted this mutation to be of 'uncertain significance'. This gene mutation may cause Ehlers-Danlos syndrome and aortic aneurysm. According to review of the literature, it was noted that all of the mutation sites determined in the current study are novel mutation sites that have not been previously reported to the best of our knowledge. Samples obtained from the parents of certain patients were also examined by Sanger sequencing, however, these parents did not carry the identified genes mutations. The results should be further verified in an animal model, such as zebra fish or mouse.

When considering all forms of genetic sequencing technology, the advantages of targeted NGS are evident. Firstly, the amount of tedious and repetitive work for researchers is reduced, owing to the fact that this method can rapidly analyze large quantities of genetic information. NGS enables thousands of genes to be analyzed simultaneously, or a smaller subset of genes (a 'mini-genome' or disease-specific panel) to be examined in a single assay. However, the limitation of sample size and the possibility of leak detection of base point mutation exist in SNP array technology. Secondly, targeted NGS not only allows focusing on specific genes associated with pathological expression, but can also improve the coverage and expressive quality of exons due to its efficient enrichment. Large-scale parallel sequencing of a specifically selected part of the genome (for example, the exome or a specific set of genes relevant to a disease phenotype) leads to a higher sequencing coverage as compared with that of whole-genome sequencing (49). Furthermore, for a specific phenotype or disease, targeted sequencing has lower cost and is more rapid than whole exome sequencing, since this technology reduces the genetic discovery that may be irrelevant to the disease (49). In addition, targeted NGS may be more clinically useful in comparison with other sequencing techniques, owing to faster turnaround time (reduced sequencing volume and associated data analysis), higher and more reliable coverage, and the ability to avoid incidental findings. However, this method is associated with certain disadvantages including the limitation of requiring known virulence genes and its lack of suitability for a single sample.

Notably, the implementation of NGS in clinical practice has altered the way genetic counsellors and other clinicians approach genetic testing. Molecular diagnostics may now be performed at an early stage of disease, often enabling a broader set of therapeutic options and a lengthened window of opportunity to ameliorate disease progression (50). The identification of underlying genetic defects can also improve diagnosis of the disease prior to genetic counselling and enable prenatal testing.

In conclusion, using targeted NGS technology, the present study determined 10 individual mutations (58.8\%) in candidate disease genes, which are possible causes of CHD and CLP in patients. The targeted NGS was demonstrated to be an effective and accurate method for providing a specific diagnosis of CHD and CLP, despite the presence of diverse phenotypes.

\section{Acknowledgements}

The authors would like to thank the State Key Laboratory of Medical Genetics of China (Changsha, China) for the technical assistance provided.

\section{Funding}

This study was supported by the Hunan Provincial Natural Science Foundation of China (grant no. 2015JJ4085) and the Scientific Research Foundation for the Returned Overseas Chinese Scholars, State Education Ministry (2014; grant no. 1685).

\section{Availability of data and materials}

The datasets used and/or analyzed during the current study are available from the corresponding author on reasonable request.

\section{Authors' contributions}

HB and TZ conceived and designed the study, and drafted the manuscript. $\mathrm{HB}$ and LL collected the data. HB, TZ and SH were involved in data cleaning and verification. $\mathrm{HB}, \mathrm{TZ}$ and ZT analyzed the data. All authors were involved in the final draft of the manuscript.

\section{Ethics approval and consent to participate}

The study protocol was approved by the Review Board at The Second Xiangya Hospital of Central South University (China), and the relatives of study subjects provided informed consent. All experiments were performed in accordance with relevant guidelines and regulations.

\section{Patient consent for publication}

Written informed consent was obtained from the their parent, guardian or next of kin for the publication of any associated data and accompanying images.

\section{Competing interests}

The authors declare that they have no competing interests.

\section{References}

1. Liang CD, Huang SC and Lai JP: A survey of congenital heart disease in patients with oral clefts. Acta Paediatr Taiwan 40: 414-417, 1999.

2. Barbosa MM, Rocha CM, Katina T, Caldas M, Codorniz A and Medeiros C: Prevalence of congenital heart diseases in oral cleft patients. Pediatr Cardiol 24: 369-374, 2003.

3. Bill J, Proff P, Bayerlein T, Weingaertner J, Fanghänel J and Reuther J: Treatment of patients with cleft lip, alveolus and palate-a short outline of history and current interdisciplinary treatment approaches. J Craniomaxillofac Surg 34 (Suppl 2): S17-S21, 2006.

4. Ho KS, South ST, Lortz A, Hensel CH, Sdano MR, Vanzo RJ, Martin MM, Peiffer A, Lambert CG, Calhoun A, et al: Chromosomal microarray testing identifies a $4 p$ terminal region associated with seizures in Wolf-Hirschhorn syndrome. J Med Genet 53: 256-263, 2016.

5. Biswas AB and Furniss F: Cognitive phenotype and psychiatric disorder in 22q11.2 deletion syndrome: A review. Res Dev Disabil 53-54: 242-257, 2016.

6. Poelmans S, Kawamoto T, Cristofoli F, Politis C, Vermeesch J, Bailleul-Forestier I, Hens G, Devriendt K, Verdonck A and Carels C: Genotypic and phenotypic variation in six patients with solitary median maxillary central incisor syndrome. Am J Med Genet A 167A: 2451-2458, 2015.

7. Abulezz TA: Cleft lip and palate: An experience of a developing center in egypt. J Craniofac Surg 28: e731-e734, 2017. 
8. Elliott AM, Simard LR, Coghlan G, Chudley AE, Chodirker BN, Greenberg CR, Burch T, Ly V, Hatch GM and Zelinski T: A novel mutation in KIAA0196: Identification of a gene involved in Ritscher-Schinzel/3C syndrome in a First Nations cohort. J Med Genet 50: 819-822, 2013.

9. Tang M, Yang YF, Xie L, Chen JL, Zhang WZ, Wang J, Zhao TL, Yang JF and Tan ZP: Duplication of 10q22.3-q23.3 encompassing BMPR1A and NGR3 associated with congenital heart disease, microcephaly, and mild intellectual disability. Am J Med Genet A 167A: 3174-3179, 2015.

10. Zeng H, Tang JG, Yang YF, Tan ZP and Tan JQ: A novel homozygous SACS mutation identified by whole-exome sequencing in a consanguineous family with autosomal recessive spastic ataxia of charlevoix-saguenay. Cytogenet Genome Res 152: 16-21, 2017.

11. Guo T, Tan ZP, Chen HM, Zheng DY, Liu L, Huang XG, Chen P, Luo $\mathrm{H}$ and Yang YF: An effective combination of whole-exome sequencing and runs of homozygosity for the diagnosis of primary ciliary dyskinesia in consanguineous families. Sci Rep 7: 7905, 2017.

12. Koestenberger M: Transthoracic echocardiography in children and young adults with congenital heart disease. ISRN Pediatr 2012: 753481, 2012.

13. Allori AC, Mulliken JB, Meara JG, Shusterman S and Marcus JR: Classification of Cleft Lip/Palate: Then and now. Cleft Palate Craniofac J 54: 175-188, 2017.

14. Gatti GL, Freda N, Giacomina A, Montemagni M and Sisti A: Cleft lip and palate repair. J Craniofac Surg 28: 1918-1924, 2017.

15. Hu S, Yang Y, Liu L, Tan Z and Zhao T: High-resolution single nucleotide polymorphism arrays identified an atypical microdeletion of the Williams-Beuren syndrome interval in a patient presenting with a different phenotype. Mol Med Rep 15: 2709-2712, 2017

16. Liu L, Bu H, Yang Y, Tan Z, Zhang F, Hu S and Zhao T: A targeted, next-generation genetic sequencing study on tetralogy of fallot, combined with cleft lip and palate. J Craniofac Surg 28 : e351-e355, 2017.

17. Chen JL, Zhu X, Zhao TL, Wang J, Yang YF and Tan ZP. Rare copy number variations containing genes involved in RASopathies: Deletion of SHOC2 and duplication of PTPN11. Mol Cytogenet 7: 28, 2014

18. Hu CH, Liu YF, Yu JS, Ng YY, Chen SJ, Su PH and Chen JY: A MID1 gene mutation in a patient with Opitz G/BBB syndrome that altered the 3D structure of SPRY domain. Am J Med Genet A 158A: 726-731, 2012.

19. Jongmans MC, Admiraal RJ, van der Donk KP, Vissers LE, Baas AF, Kapusta L, van Hagen JM, Donnai D, de Ravel TJ, Veltman JA, et al: CHARGE syndrome: The phenotypic spectrum of mutations in the CHD7 gene. J Med Genet 43: 306-314, 2006.

20. Tan ZP, Xie L, Deng Y, Chen JL, Zhang WZ, Wang J, Yang JF and Yang YF: Whole-exome sequencing identifies Y1495X of SCN5A to be associated with familial conduction disease and sudden death. Sci Rep 4: 5616, 2014.

21. Zhang X, Chen Y, Zhao S, Markljung E and Nordenskjöld A: Hypospadias associated with hypertelorism, the mildest phenotype of Opitz syndrome. J Hum Genet 56: 348-351, 2011.

22. Muramatsu Y, Kosho T, Magota M, Yokotsuka T, Ito M, Yasuda A Kito O, Suzuki C, Nagata Y, Kawai S, et al: Progressive aortic root and pulmonary artery aneurysms in a neonate with Loeys-Dietz syndrome type 1B. Am J Med Genet A 152A: 417-421, 2010.

23. Husu E, Hove HD, Farholt S, Bille M, Tranebjærg L, Vogel I and Kreiborg S: Phenotype in 18 Danish subjects with genetically verified CHARGE syndrome. Clin Genet 83: 125-134, 2013.

24. Srivastava D: HAND proteins: Molecular mediators of cardiac development and congenital heart disease. Trends Cardiovasc Med 9: 11-18, 1999.

25. Sisti A and Oranges CM: Evidence-based medicine: Unilateral cleft lip and nose repair. Plast Reconstr Surg 136: 118e-119e, 2015.

26. Pinson L, Augé J, Audollent S, Mattéi G, Etchevers H, Gigarel N, Razavi F, Lacombe D, Odent S, Le Merrer M, et al: Embryonic expression of the human MID1 gene and its mutations in Opitz syndrome. J Med Genet 41: 381-386, 2004.

27. Short KM, Hopwood B, Yi Z and Cox TC: MID1 and MID2 homo- and heterodimerise to tether the rapamycin-sensitive PP2A regulatory subunit, alpha 4, to microtubules: Implications for the clinical variability of X-linked Opitz GBBB syndrome and other developmental disorders. BMC Cell Biol 3: 1, 2002.

28. Hüning I, Kutsche K, Rajaei S, Erlandsson A, Lovmar L, Rundberg J and Stefanova M: Exon 2 duplication of the MID1 gene in a patient with a mild phenotype of Opitz G/BBB syndrome. Eur J Med Genet 56: 188-191, 2013.
29. Migliore C, Athanasakis E, Dahoun S, Wonkam A, Lees M, Calabrese O, Connell F, Lynch SA, Izzi C, Pompilii E, et al: Complex rearrangement of the exon 6 genomic region among Opitz G/BBB syndrome MID1 alterations. Eur J Med Genet 56: 404-410, 2013.

30. Preiksaitiene E, Krasovskaja N, Utkus A, Kasnauskiene J, Meskiene R, Paulauskiene I, Valeviciene NR and Kucinskas V: R368X mutation in MID1 among recurrent mutations in patients with X-linked Opitz G/BBB syndrome. Clin Dysmorphol 24: 7-12, 2015.

31. Ji X, Xing Y, Xu Y, Liu Y, Chen Y, Tao J and Xiao B: A novel mutation in MID1 in a patient with X-linked Opitz G/BBB syndrome. Gene 537: 140-142, 2014.

32. Van den Veyver IB, Cormier TA, Jurecic V, Baldini A and Zoghbi HY: Characterization and physical mapping in human and mouse of a novel RING finger gene in Xp22. Genomics 51: 251-261, 1998

33. Schweiger S and Schneider R: The MID1/PP2A complex: A key to the pathogenesis of Opitz $\mathrm{BBB} / \mathrm{G}$ syndrome. Bioessays 25 : 356-366, 2003

34. Van Laer L, Dietz H and Loeys B: Loeys-Dietz syndrome. Adv Exp Med Biol 802: 95-105, 2014

35. Loeys BL, Schwarze U, Holm T, Callewaert BL, Thomas GH, Pannu H,De Backer JF, Oswald GL, Symoens S, Manouvrier S, et al: Aneurysm syndromes caused by mutations in the TGF-beta receptor. N Engl J Med 355: 788-798, 2006

36. Dudas M, Kim J, Li WY, Nagy A, Larsson J, Karlsson S, Chai Y and Kaartinen V: Epithelial and ectomesenchymal role of the type I TGF-beta receptor ALK5 during facial morphogenesis and palatal fusion. Dev Biol 296: 298-314, 2006.

37. Li WY, Dudas M and Kaartinen V: Signaling through Tgf-beta type I receptor Alk5 is required for upper lip fusion. Mech Dev 125: 874-882, 2008.

38. Valdmanis PN, Meijer IA, Reynolds A, Lei A, MacLeod P, Schlesinger D, Zatz M, Reid E, Dion PA, Drapeau P and Rouleau GA: Mutations in the KIAA0196 gene at the SPG8 locus cause hereditary spastic paraplegia. Am J Hum Genet 80: 152-161, 2007.

39. Jahic A, Kreuz F, Zacher P, Fiedler J, Bier A, Reif S, Rieger M, Krüger S, Beetz C and Plaschke J: A novel strumpellin mutation and potential pitfalls in the molecular diagnosis of hereditary spastic paraplegia type SPG8. J Neurol Sci 347: 372-374, 2014.

40. Dauber A, Golzio C, Guenot C, Jodelka FM, Kibaek M, Kjaergaard S, Leheup B, Martinet D, Nowaczyk MJ, Rosenfeld JA, et al: SCRIB and PUF60 are primary drivers of the multisystemic phenotypes of the 8q24.3 copy-number variant. Am J Hum Genet 93: 798-811, 2013.

41. Pagon RA, Graham JM Jr, Zonana J and Yong SL: Coloboma, congenital heart disease, and choanal atresia with multiple anomalies: CHARGE association. J Pediatr 99: 223-227, 1981.

42. Cho HJ, Song MH, Choi SY, Kim J, Lee J, Kim UK, Bok J and Choi JY: Genetic analysis of the CHD7 gene in Korean patients with CHARGE syndrome. Gene 517: 164-168, 2013.

43. Zentner GE, Layman WS, Martin DM and Scacheri PC: Molecular and phenotypic aspects of CHD7 mutation in CHARGE syndrome. Am J Med Genet A 152A: 674-686, 2010.

44. Picard C, McCarl CA, Papolos A, Khalil S, Lüthy K, Hivroz C, LeDeist F, Rieux-Laucat F, Rechavi G, Rao A, et al: STIM1 mutation associated with a syndrome of immunodeficiency and autoimmunity. N Engl J Med 360: 1971-1980, 2009.

45. Szumska D, Pieles G, Essalmani R, Bilski M, Mesnard D, Kaur K, Franklyn A, El Omari K, Jefferis J, Bentham J, et al: VACTERL/caudal regression/Currarino syndrome-like malformations in mice with mutation in the proprotein convertase Pcsk5. Genes Dev 22: 1465-1477, 2008.

46. Ramos Arroyo MA, Weaver DD and Beals RK: Congenital contractural arachnodactyly. Report of four additional families and review of literature. Clin Genet 27: 570-581, 1985.

47. Chiba S: Notch signaling in stem cell systems. Stem Cells 24 2437-2447, 2006

48. Di Donato I, Bianchi S, De Stefano N, Dichgans M, Dotti MT, Duering M, Jouvent E, Korczyn AD, Lesnik-Oberstein SA, Malandrini A, et al: Cerebral autosomal dominant arteriopathy with subcortical infarcts and leukoencephalopathy (CADASIL) as a model of small vessel disease: Update on clinical, diagnostic, and management aspects. BMC Med 15: 41, 2017.

49. Nijman IJ, Mokry M, van Boxtel R, Toonen P, de Bruijn E and Cuppen E: Mutation discovery by targeted genomic enrichment of multiplexed barcoded samples. Nat Methods 7: 913-915, 2010.

50. Pei Y and Watnick T: Diagnosis and screening of autosomal dominant polycystic kidney disease. Adv Chronic Kidney Dis 17: $140-152,2010$ 